the little things that people get annoyed at, like improper scheduling or inadequate audiovisual equipment. I think that in all these respects we came out very well."
-ACRL's Fourth National Conference will be held in Baltimore in April, 1986. We hope you will join us then when ACRL returns to the East. GME.

\title{
Using the online catalog effectively
}

\author{
By Marcella Stark \\ History and Afro-American Studies Librarian \\ Syracuse University
}

\section{A seminar, specifically designed for faculty members, on how to use the Syracuse University system.}

\begin{abstract}
$\mathbf{T}_{\mathrm{H}}$ he online public access catalog is becoming a reality in many institutions. Thus, instruction designed to show the capabilities of the online system is necessary, not only to overcome initial resistance to a new system, but also to ensure that the maximum capabilities of the system are apparent to users.

Librarians need to instruct faculty as well as students. Because they may find that faculty resist library instruction for themselves, librarians should seek reinforcements on the campus to aid in any instruction program. The following is a description of the Syracuse University Libraries cooperation with a respected campus institution to develop an instruction program for university faculty.

Syracuse University Libraries have had an online public access catalog, SULIRS (Syracuse University Libraries Information Retrieval System) since January 1981. Before the catalog was put in place, a slide-tape lecture, designed and presented by the director of libraries, prepared faculty for the change. There was publicity in the campus media. Users were provided with booklets that described basic searches.
\end{abstract}

At the outset the system provided author and tithe access only via OCLC derived search keys to a database of approximately 500,000. After five months, the search key approach was abandoned and SULIRS provided keyword searching via author, title, series title, call number, and subject. Free-text key word searching was possible across the title and subject fields. Initially, there were few HELP messages or system prompts imbedded in the SULIRS program; extensive HELP messages were added late in 1983. From the beginning, however, the Boolean AND was implied; the Boolean NOT being added later. ${ }^{1}$

SULIRS was available only in the libraries until the summer of 1983, when it was made available from any terminal on campus. Individuals with a terminal and modem could access SULIRS via the telephone and the university computing center.

Since most of the terminals in the library were located near the reference desk, reference librari-

${ }^{1}$ Gregory N. Bullard, "The Syracuse University Libraries Information Retrieval System," Research Libraries in OCLC: A Quarterly, no. 7 (1982):1-2. 
ans initially provided training when requested. Since the spring of 1983 , librarians have been stationed directly by the terminals during peak hours to provide individual assistance. Librarians observed, however, that while both faculty and students easily mastered the basics of searching, they used card catalog strategies instead of taking advantage of the dynamics of online searching. For

\section{The seminar focused on}

\section{search techniques unique to}

\section{an online catalog.}

example, someone searching for Patriotic Gore by Edmund Wilson might proceed by entering "Wilson, Edmund," and SULIRS would respond with 71 items. The user would read through the list until Patriotic Gore appeared. In other words, searchers were not using the keyword capabilities of the system, combining the author's name with a significant word in the title, say Patriotic, which would immediately retrieve 3 items, saving time and relieving the tedium of searching.

Some faculty SULIRS training was attempted during the previous two years at the annual campus-wide Seminar on Teaching. Sponsored by the University Senate Committee on Instruction, the Seminar brings experienced faulty with reputations as teachers together with newer faculty to share information about the resources at the university that support teaching. A librarian is a member of the Senate Committee and coordinated the library-related presentations at the Seminar.

While the presentation never seemed quite to fit into the Seminar, it received very positive evaluations from those who attended. The librarians involved developed a presentation directed at a faculty audience. As the Seminar became more widely attended, the committee often talked about developing smaller workshops based on a single topic of interest to faculty. The library presentation seemed ripe for such a separate program. The director of libraries, who attended the Seminar presentations, also suggested that the presentation be re-worked into a separate program to be sponsored by the $\mathrm{Li}$ braries and the Senate Committee.

Almost concurrently, the librarians at Syracuse realized that they themselves were not aware of the full capabilities of SULIRS. Two members of the Cataloging Department, which is responsible for

${ }^{2}$ Elaine Coppola, "Who Trains the Trainer? Library Staff Are OPAC Users, Too," Library Hi Tech 1 (Winter 1983):36-38. the development and maintenance of the database, were asked to produce a workshop on SULIRS for librarians. These were held in December 1982 and January $1983 .^{2}$

Late in the spring semester of 1983, the director of libraries appointed an ad hoc group to develop a presentation on SULIRS directed at the teaching faculty. It consisted of the librarians who developed the Seminar presentation and the catalog librarians responsible for the in-house workshops. Official sponsorship of the Senate Committee was sought and received. The presentation to be developed was called a "seminar," using the name of other programs sponsored by that group. ${ }^{3}$

Originally the planning group thought in terms of a two-hour presentation. On faculty advice, however, they decided that more people would attend a program limited to one hour. From previous experience, they assumed that most participants knew the basic mechanics of searching SULIRS. The program would concentrate on searching techniques unique to an online catalog.

Because the university computing center had a classroom equipped with a projection system that displayed information from a computer terminal, the planning group decided to hold the Seminar there. The room had telephone jacks where additional terminals could be connected to provide hands-on experience and individual instruction. Not only could the room hold forty people comfortably, the librarians believed that holding the Seminar away from the library would demonstrate that the online catalog was available from every terminal on campus.

The Seminar was offered three times in October 1983, late in the afternoon on a Tuesday, Wednesday and Thursday in succeeding weeks. The group planned a lecture/demonstration lasting approximately thirty-five minutes with the remainder of the hour devoted to questions and individual instruction. The lecture drew searching examples from all disciplines. One person spoke, a second typed the search. Previous experience with one person performing both functions indicated that a smoother performance would result if two people coordinated efforts. Rehearsals were held to make sure the presentation would be completed in the time allotted.

A letter, co-signed by all the sponsoring groups, was sent three weeks in advance of the Seminar. It described the goals and content of the presentation and requested participants to make a reservation.

Besides sending notices and preparing the lecture demonstration, the planning group thought other preparations necessary. Three handouts were prepared. Copies of the booklets describing

${ }^{3}$ Group members are Donald C. Anthony (director of libraries), Marcella Stark (history and AfroAmerican studies librarian), Elaine Coppola, Caroline Long, Barbara Opar, Charles Tremper, and Mary Anne Waltz. 


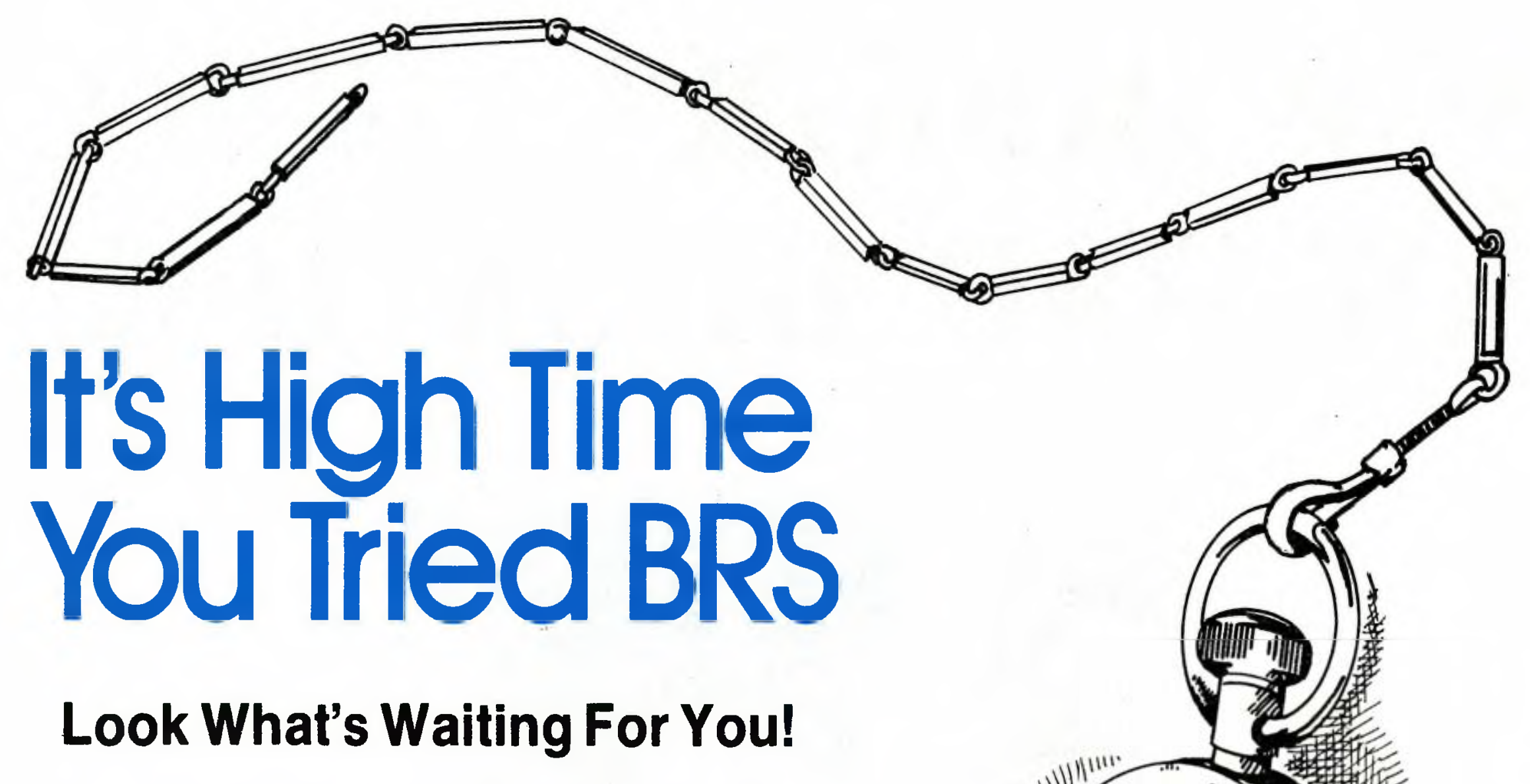

- 82 databases-37 available exclusively from BRS-give you access to timely, unique information.

- Convenient grouping of databases by major subject categories provides you with a breadth of online information.

- Simple interactive language makes BRS easy to learn and use, whether you're an online searching pro or a first-time user.

- Available when and where you need it, home or work, 22 hours every working day, plus weekend and holiday hours.

- Wide choice of access plans lets you tailor your usage to your budget.

Return the coupon for timely information on this powerful, online search service.

If's Time I Learned More!

$\square$ Please send details on BRS senvices, rates and access plans.

I'm Ready To Sign Up Now!

$\square$ Please send me the necessary forms.

Mail to: BRS, 1200 Route 7, Latham, NY 12110
NAME

COMPANY/INSTITUTION

ADDRESS

CITY

STATE

ZIP

TELEPHONE ( )

CRLN 6/84 

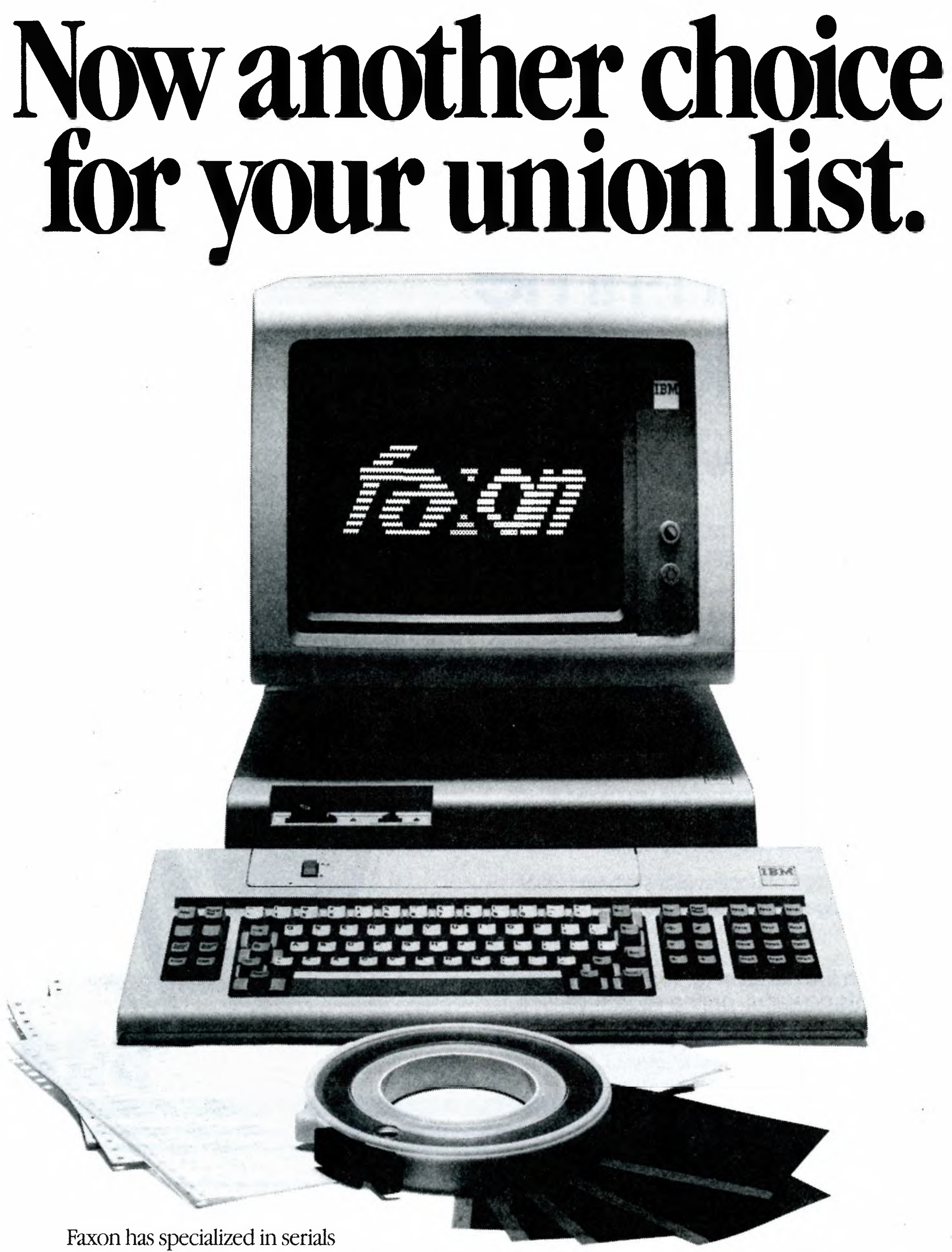

Faxon has specialized in serials

management for libraries for over 100 years. Now we're offering a Union List module on Linx, the online serials management system. Union list groups can add, share, and maintain up-to-date information on their collective serial titles and holdings.

Because we're flexible, we can handle your current machine-readable lists or save time during your manual conversion, thus saving you valuable manpower resources. Our Union List products are available now

and include both group lists and individual member lists in hard copy, tape, or microfiche.

Make a choice soon! You don't have to use Faxon's subscription service to take advantage of our Union List. Call our Sales Department at (800) 225-6055 or (617) 329-3350 (collect)

and arrange for a demonstration of Faxon's Union List.

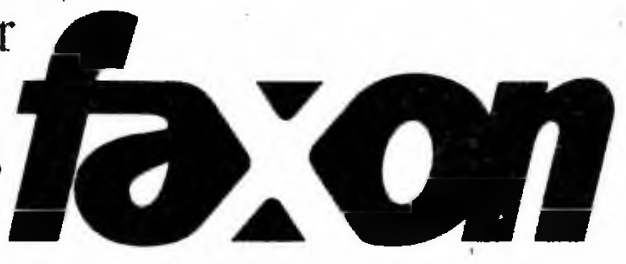

The Faxon Company, 15 Southwest Park, Westwood, MA 02090 
basic searches were collected, and a description of the means of accessing SULIRS from outside the libraries was written. With the aid of a university specialist on evaluation, the planning group compiled a short evaluation form asking the participants to rate quality of presentation, to suggest improvements, and library topics for future seminars.

Of the seventy-six people who made reservations, sixty attended. Initial questioning revealed that the vocal members of the first group were relatively inexperienced SULIRS users. As the lecture was punctuated by questions, insufficient time remained for further demonstrations and hands-on experience. The second group matched expectations-they were SULIRS users and wanted to learn more. The lecture evolved into a discussion with the participants contributing searching examples, raising questions and posing problems that followed from the lecture. Attendees remained after the hour to continue searching. The last presentation had the smallest attendance; the lecture was accomplished in the time allotted, and the questions were few. The form and content of all three presentations received positive evaluations. Because the second session became a seminar with the participants actively committed to the learning process, the evaluations were superlative.

Naivete and sophistication were apparent in all sessions. A participant wanted to know how to search foreign language materials. The answer was that the SULIRS used the same principle as the card catalog: titles are in the language of the item, subject headings are in English. A scientist pointed out that keyword searching made it considerably easier to locate conference papers: entering " 5 th nuclear physics," one did not have to remember if the meeting was a congress or colloquium. Because searching by call number made the shelf list available, participants expressed great interest in learning how to manipulate call numbers. Attendees were interested to learn that they could search subjects using their "terminology" as well as the indexing vocabulary of SULIRS (Library of Congress Subject Headings). It was carefully pointed out that the latter should be used for more precision in searching, the example being the difference between "intensive care" nursing (Library of Congress) and "critical care" nursing (user's term).

The comments and queries indicated that participants came from across the campus. In order to provide quick and knowledgeable responses, librarians with in-depth searching experience in both the sciences and humanities were present. It may be worth noting that while Seminar attendees were interested in online searching, none asked about the technical aspects of the computer system.

The Seminar was an experiment. It grew out of the Libraries' involvement with the faculty developed Seminar on Teaching and the Universit. Senate. Co-sponsorship of the Libraries' efforts by this respected group created additional good will for the Libraries' instruction efforts. Concurrently, the librarians had undergone in-depth training and had had active experience in observing and assisting users with the online catalog. As a result of these factors, the Seminar participants were receptive and enthusiastic.

\section{Librarians eligible for Fulbright scholarships}

The Council for International Exchange of Scholars, through the United States Information Agency, has received from agencies and embassies abroad the list of Fulbright Scholar Awards available to American scholars. Librarians and information scientists are eligible to apply for relevant programs.

Some of the 1985-1986 programs that relate to librarianship are: Indonesia, social science research techniques (ability to lecture in Indonesian required); Korea, research in Korean studies (must be currently working in Korean research program); People's Republic of China, library and information science lecturing at Beijing University or Wuhan University; Taiwan, business information systems analysis or design; Thailand, social science research (previous Thai research experience preferred); Tunisia, teaching economics of information and information systems, Institut de Presse et des Sciences d'Information, Tunis (ability to lecture in French required); and the U.S.S.R., library and information science lecturing at various Soviet institutions.

The deadline for these award programs is September 15, 1984.

Information and applications can be obtained at graduate institutions from the office of the Graduate Dean, of International Programs, or of Research and Sponsored Programs. On undergraduate campuses they are available from the office of the chief academic officer.

All applications are reviewed by recognized specialists both in the applicant's professional and academic discipline and in the chosen geographic area. The presidentially appointed Board of Foreign Scholarships makes final selections, with the agreement of agencies in the host country.

For further information, contact the Council for International Exchange of Scholars, 11 Dupont Circle, Washington, DC 20036; (202) 8334841. 


\section{Overseas library assignments on the RISE}

Librarians are also eligible to seek positions abroad through the Register for International Service in Education (RISE). RISE, administered by the Institute of International Education, is a computer-based referral service designed to enable universities, technical institutes, research centers, government ministries, and development projects outside the United States to locate qualified educators, specialists, researchers, and consultants for education-related assignments. These assignments may range in duration from a few weeks to several years.

In the past two years in which the database has been operational, about 25 openings in library science have been listed. There are currently over 500 applicants on the register, and nearly 1,700 positions in various disciplines available.

Anyone qualified to teach, consult, or conduct research at the university or other postsecondary level may place their name on the register. A fee of $\$ 45$ covers registration for a one-year period, beginning approximately 10 days from the date that IIE receives the completed application and fee. The data supplied on the registration form will be keyed into a database. Printouts will be sent to registered institutions and agencies to fill requirements which correspond to individual registrants' basic qualifications and interests.

Most assignments are in Latin America, Asia, Africa, and Oceania. Some positions offer salary and benefits equivalent or greater than U.S. levels. Transportation, housing, home leave, and support for dependents may be included. In general, however, developing countries' compensation scales are lower than those in the United States. Living and working conditions are likely to be quite different and may require flexibility and adaptation.

A new area which RISE has initiated is the listing of positions available in American and international schools abroad. While no specific library positions have been requested from such schools, openings may well exist in the future. The schools are all accredited, and the salaries are competitive and usually paid in U.S. dollars.

For application forms or further information, contact: Sandra Cervera, RISE, Institute of International Education, 809 United Nations Plaza, New York, NY 10017; (212) 883-8241.

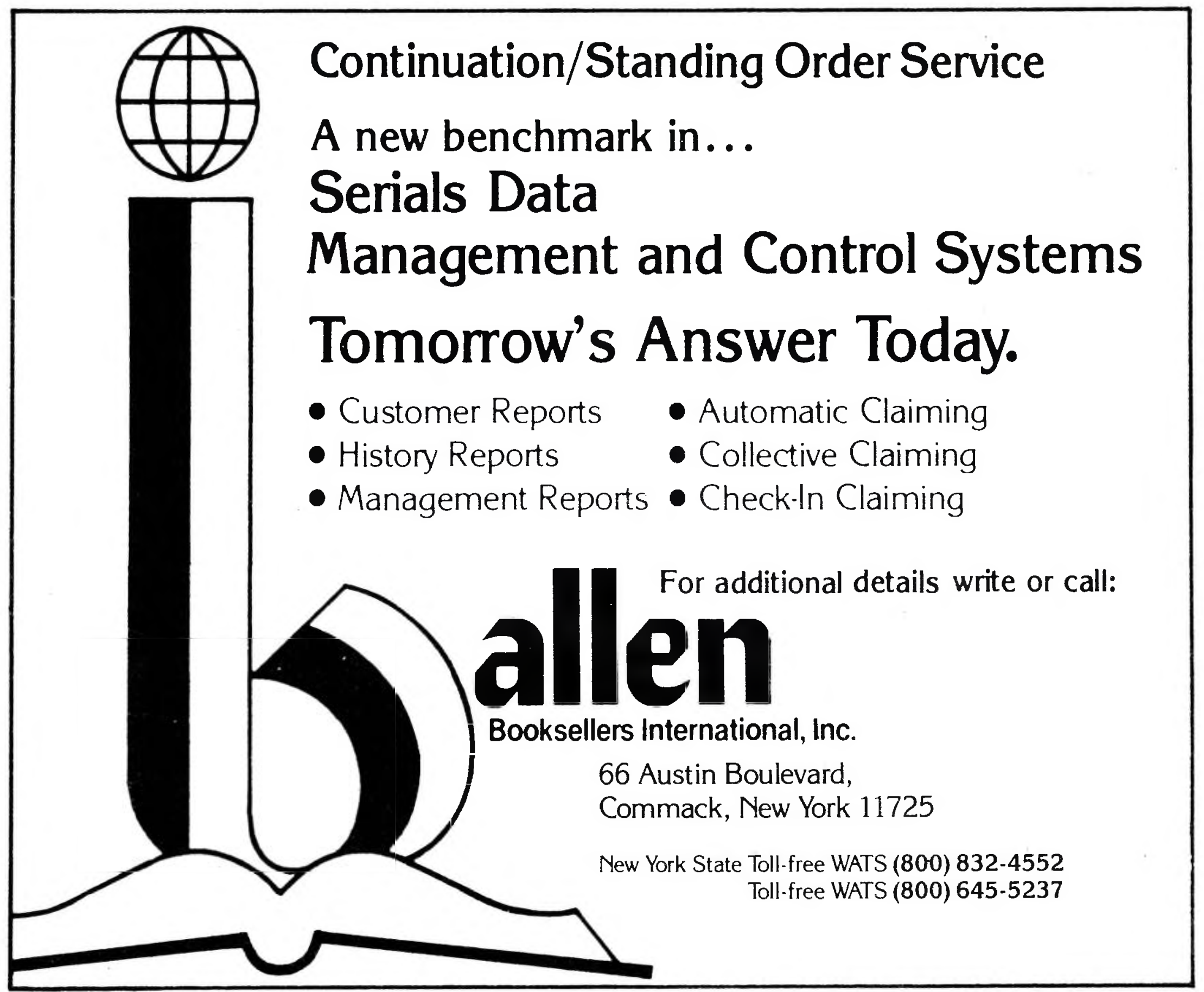

